\title{
The Study of IE Curriculum Construction and Implementation Based on Fashion Industry*
}

\author{
Weiwei Wang \\ Zhejiang Fashion Institute of Technology \\ Ningbo, China 315211
}

\begin{abstract}
This paper mainly describes the content of construction and implementation of clothing IE curriculum from the construction of talent training objectives, the formulation of curriculum standards, and the practice and innovation of teaching models based on the demand characteristics for clothing IE talents of the clothing industry clusters in Ningbo and summarizes the innovative teaching mode of strengthening the practical teaching, close cooperation between school and enterprise to achieve the integration and optimization of the curriculum system, and information-based teaching.
\end{abstract}

Keywords-clothing IE; practice teaching; curriculum system; school-enterprise cooperation; information teaching

\section{INTRODUCTION}

With the substantial increase in the cost of raw materials and labor and the change in the structure of clothing orders, the extensive management model of Chinese garment manufacturers has been unable to meet the fast-paced, lowcost, small-volume, high-efficiency, high-quality market demand, while the countries in Southeast Asia, etc. are emerging as a strong rival in apparel manufacturing, and China's garment processing industry is moving outward. These problems have become the bottleneck restricting the development of the garment manufacturing industry.

As a result, more and more clothing companies have begun to pay attention to the application of industrial engineering (IE) technology and methods, in order to reduce the production costs of enterprises, improve production efficiency, and enhance the competitiveness of enterprises.

Industrial Engineering (IE) is an applied engineering technology discipline based on scientific management. It combines the knowledge and technology of mathematics, physics, and social science to design, improve, and implement integrated systems consisting of people, materials, equipment, energy, and information. Because industrial engineering emphasizes comprehensively improving labor productivity, reducing production costs, ensuring product quality, and making the production system in optimal

*Fund Project: Research on the Flipped Classroom Teaching Model Based on MOOC - Taking the Clothing IE Course as an Example (2017 Informatization Teaching Research Project of Textile and Apparel College, Project No. ZWH-17057)

CLC number: G642.3 operation to obtain the best overall benefits, it has received much attention from all countries in the world. China's industrial engineering higher education began in 1993. First, undergraduate students were enrolled in Xi'an Jiaotong University and Tianjin University. Most of the colleges and universities classified industrial engineering as an engineering major under the Institute of Mechanical and Electrical Engineering. Students will graduate with a bachelor of engineering. Some universities have set up industrial engineering in the School of Management and grant the bachelor of management for graduates [1].

Through consulting the literature, it is found that some universities have carried out related research on how to cultivate industrial engineering talents and carry out the practical teaching mode of industrial engineering and related courses, but specifically for the application of industrial engineering in clothing enterprises, most clothing colleges involve less in teaching, and some colleges only make it as a part of the clothing production management curriculum. Research on the "Clothing IE" curriculum and the research on the cultivation of clothing IE talent are still lacking, which is not conducive to the cultivation of innovative talents in industrial engineering of clothing. Although $\mathrm{Li}$ Erliang of Henan University of Engineering mentioned the combination of clothing and industrial engineering in "Exploration of Practical Teaching of Industrial Engineering with Textile and Apparel Characteristics" [2], he mainly focused on the characteristic background of the college textile and clothing profession and studies the practice teaching link of entire industrial engineering major, and didn't specifically study the detail in the implementation of the clothing IE course.

Zhejiang Fashion Institute of Technology opened the "Clothing IE" course in 2009. As a new course in a local higher vocational college in Ningbo, it attaches great importance to teaching research and reform in the construction process. Based on cultivating clothing IE professional and technical talents needed by local economic development and the demand characteristics of clothing IE talents in the Ningbo regional clothing industry cluster, we will continue to explore and practice the innovative teaching of the curriculum, and strive to cultivate innovative clothing IE talents. 


\section{CONSTRUCTION OF THE TALENT TRAINING GOAL}

Ningbo, as one of the garment manufacturing centers in Zhejiang Province has the typical characteristics of small and medium-sized garment enterprises occupying the majority, low labor efficiency, weak management ability, and small R\&D investment, which have become the biggest difficulties restricting the upgrading of garment industry in Ningbo. Therefore, the improvement of production efficiency and benefit is a key issue that must be addressed in the upgrading of the garment industry in Ningbo. In particular, under the influence of external factors such as slowing domestic demand growth, slow recovery of external demand, and rising manufacturing costs, enterprises urgently need to implement lean management by applying IE technologies and methods, improving utilization efficiency of production resources, reducing production costs, improving production efficiency, realizing rapid response of enterprises and enhancing the internal competitiveness of enterprises.

Under this background, according to the production characteristics of Ningbo garment manufacturing enterprises and the needs of IE jobs, it is determined that the talent training target requirements of the clothing IE curriculum are to train clothing IE professionals needed by regional economy, closely combine teaching with the production practices of local enterprises, build a systematic practical teaching system, attaches importance to the application of IE theories and methods to the practical problems of garment manufacturing enterprises and cultivate applied talents. Achieving this goal is a complex systematic engineering, including setting up a scientific curriculum system, establishing a reasonable knowledge structure, and completing necessary practical teaching.

\section{FORMULATION OF CURRICULUM STANDARD}

As a discipline, industrial engineering was formed in the scientific management movement of American Taylor and others in the late 19th century. People called IE in the Taylor era as traditional IE or classic IE, including time research, motion research, factory layout, material handling, production plan and scheduling, etc. After the Second World War, IE was called Modern IE that integrates many new disciplines and high-tech based on the theory of operations research and systems engineering, and the advanced means of computer. In the American Industrial Engineering Handbook, according to the statistics of actual situation of 667 companies in the United Kingdom, 32 kinds of methods commonly used by IE are summarized [3]. It can be seen that the range of IE content is wide, but how to determine the content of teaching and how to enable students to master the core content of IE technology required by clothing enterprises in a course is a real problem. Therefore, in the early stage of developing the curriculum standards, we visited a large number of Ningbo garment manufacturing enterprises, such as Ningbo Shenzhou Knitting Garment Co., Ltd., and other enterprises that have implemented IE technology within the enterprise and the garment enterprises with IE needs. Combined with the needs of enterprises and actual work, we analyzed the tasks of the IE job and the skill requirements of the work tasks in the enterprise, designed the eight project tasks including "process analysis", "calculation of work time", "action analysis made by the predetermined action analysis system", "setting process price", "following up the large-scale production process and improvement process, "arranging assembly line", "balancing and improving the assembly line", and "analyzing and improving the site layout and material circulation route of garment factories", as shown in "Fig. 1". The content of the course is combined with the practical application of the production line of the enterprise and each task is set with knowledge teaching objectives, skill training objectives, design of work method and requirements on completion time. The curriculum standard that meets the enterprise is formulated, and the training of students' professional ability is highlighted.

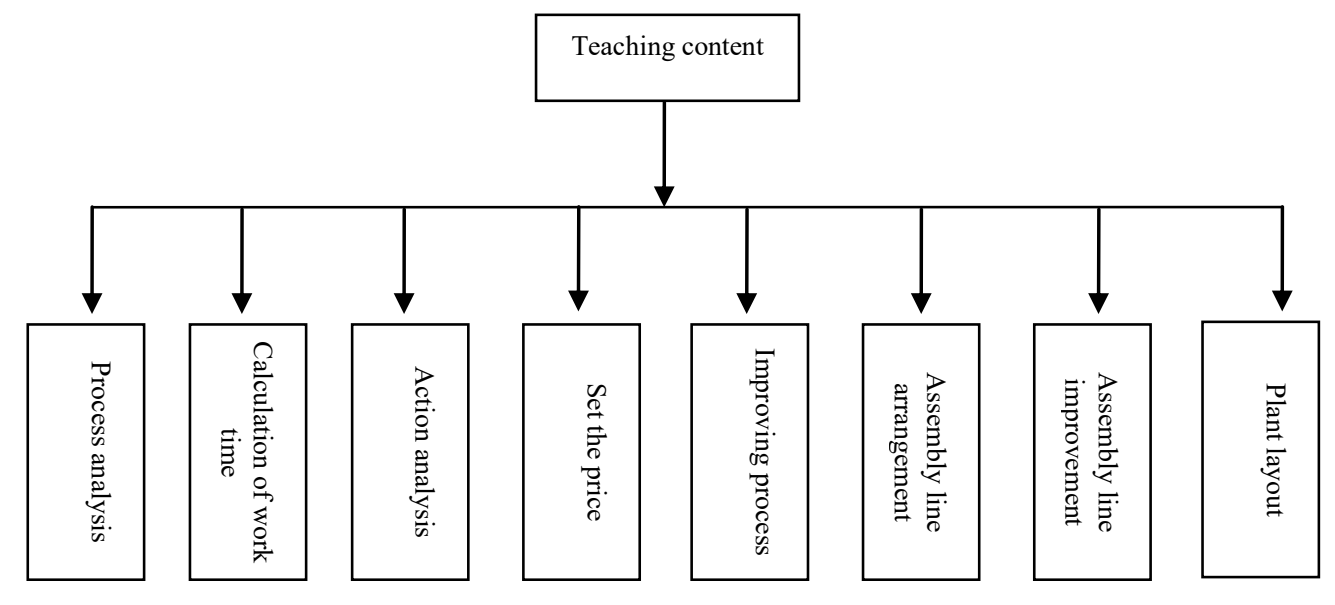

Fig. 1. The eight project tasks. 


\section{Practice ANd InNovation of Teaching Mode}

\section{A. Exploration of Practical Teaching Connecting Enterprises}

The application of IE method emphasizes practical operation and the clothing IE course also requires students to combine knowledge, practice, experience and skill perfectly, and emphasizes the integration of practice into the teaching process of the curriculum knowledge in clothing IE. The lack of practice links makes it impossible for students to skillfully apply the theoretical knowledge of technology. Under the guidance of this concept, with the orientation of IE in practical application direction and job position of garment enterprises, we should constantly make innovation in practical teaching content and teaching methods relying on the industrial practice of Ningbo garment manufacturing industry, forming a practical teaching system that connects industry and has various forms.

1) "Enterprise production practices" in the classroom: IE technology is inseparable from the production site of the enterprise. [4]In the course, the teacher uses camera shooting and information technology to collect the production scene videos and pictures of Ningbo garment manufacturing enterprises according to the teaching content before the class, and build a video material library for classroom teaching. Under the guidance of the teacher, the students use the course knowledge learned to analyze the situation in the video. Compared with the traditional classroom teaching, this method fully mobilizes students' interest in learning, enhances the intuitiveness of the course, makes it easy for students to understand and improves the teaching effect. In addition, compared with the practice in enterprise, the teaching cost is also greatly reduced.

2) The systematic practice link of entering the enterprise: Aiming at the problem of insufficient systematic comprehensive practice training in the classroom, this paper puts forward the comprehensive practical teaching link of "entering the enterprise to solve problems". Through the successful cooperation with Ningbo clothing enterprises, we establish the clothing IE curriculum practice base, so that students have the opportunity to "enter the enterprise, know the enterprise, and regard the production workshop as the classroom of the school." This practical teaching mode completely abandons the traditional model based on teacher teaching, and embodies the teaching mode that takes the unity of students' learning and doing as the main body, which can comprehensively train students' innovative ability, practical ability and learning ability [4].

\section{B. Integration and Optimization of Course System}

According to the idea of "more convergence between courses can achieve better integration of topics and concepts" proposed by Academician Guo Wei [5], after several years of construction, the IE course has constructed the curriculum system integrating clothing IE courses teaching, graduation project of clothing IE and clothing IE post-internship. It closely related to several relevant courses, and gradually consolidated the IE curriculum system structure from theory to practice. As shown in "Fig. 2", the system scatters the enhancement and practice of clothing IE knowledge into multiple teaching links. Since 2010, students completed the IE course in the fourth semester, and in the fifth and sixth semester, they completed internships in IE positions in apparel companies, and completed graduation design or graduation thesis. The content or topic of the graduation design is directly related to the actual needs of the enterprise, the problem solving and the specific content of the student's internship. On the one hand, the students have an intuitive and perceptual understanding of the job and the completed graduation design project, which is convenient for the completion of the graduation design, avoiding the imagination without actual practice of the previous graduation design; on the other hand, the individualization of the production practice and the environment can greatly stimulate students to use their knowledge to solve practical problems and cultivate their innovative thinking and ability. The result of the graduation design is subject to the test of actual production, and the company and the school send technical personnel and teachers to jointly participate in students' defenses.

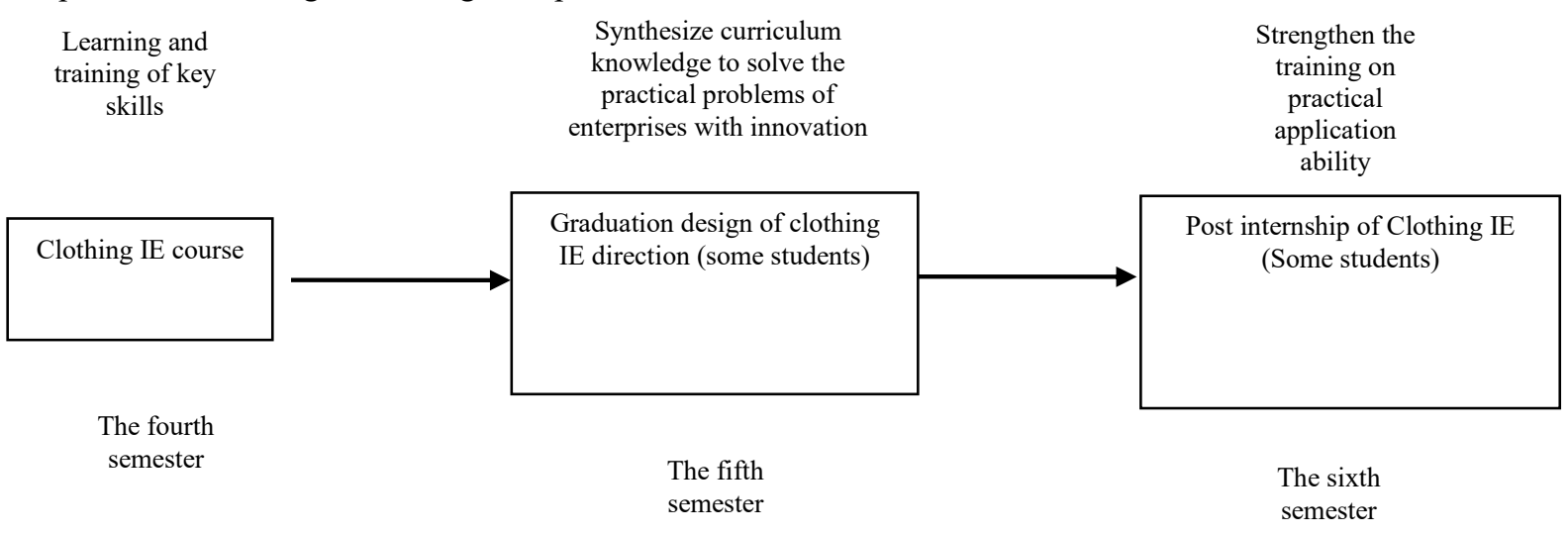

Fig. 2. The IE curriculum system structure. 


\section{The Use of Information-based Teaching Methods}

With the development of technology, the relationship between teaching and information technology is getting close. In the National Medium and Long Term Education Reform and Development Plan (2010-2020), the plan of "accelerating the process of educational informationization" is clearly put forward. The teaching innovation of clothing IE course also responds to the development trend of teaching reform. Based on making full use of modern information technology, it makes multimedia teaching courseware, builds multimedia material library, makes micro-courses, develops online courses, and tries heuristic teaching method based on network information platform and information technology to change traditional teaching and learning mode, carries on the innovation of classroom teaching, and promotes the improvement of teaching quality and teaching effect.

1) Producing vivid multimedia courseware to improve teaching results: In order to mobilize students' enthusiasm and initiative in classroom learning, enrich students' knowledge scope, stimulate students' interest, activate students' thinking, and cultivate students' innovative ability, PPT, Photoshop and other software are uses to produce multimedia teaching courseware integrating sound, image and video. . Vivid, lively and intuitive multimedia courseware not only allows students to understand the status quo of garment manufacturing enterprises in the classroom, but also transmits a large amount of information accurately and timely, so that students can better understand the knowledge content taught in teachers and textbooks.

2) Building a multimedia material library, and making micro-courses, to enrich teaching forms: In order to enrich the teaching forms and means, teachers use the investment of scientific research and teaching reform projects to lead the students' team to actively build the teaching materials including video resource library, multimedia material library and teaching micro video supporting the clothing IE course by taking the opportunities of entering enterprises in the graduation design and post-internship links. Because these materials are directly from the production line of the enterprise, many of them are the latest technological achievements of the enterprise, which provides a good resource for classroom practice teaching. Teachers can select the pictures, videos and cases as required according to the content of the class for explanation and practice, which is convenient for the implementation of classroom teaching and the understanding of students. At the same time, students' problems solving and implementing ability has also been trained in the process of participating in the teaching and research of projects with teachers.

3) School and enterprise cooperate to develop teaching software and simulate real work scenarios: The basic work of IE is inseparable from the collection and statistics of enterprise production data. It is difficult to realize data sharing and convenient query by relying solely on EXCEL, WORD and other software. At the same time, IE work involves a lot of data calculation and analysis, so the application of clothing IE software will greatly facilitate the work in this area. In the process of building the IE course, we discuss with the cooperative enterprise, learn from the experience and database of the clothing IE software in the enterprise, and jointly develop the clothing IE teaching software suitable for classroom teaching. There are many similarities between the teaching software and the software actually used in the enterprise, and a large amount of data in the software database is derived from the real data of the enterprise, which enhances the sense of situation and authenticity of the student's work; on the other hand, the students master the operational skills of relevant software in the classroom, which can shorten the student's postadaptation cycle and facilitate the implementation of graduation design and internships.

4) Developing an online course teaching platform to promote independent learning: In order to adapt to information-based teaching reform and meet the needs of students' online learning, this course has built a clothing IE MOOC which has been launched on the Ningbo MOOC Union platform and the Zhejiang boutique online open course sharing platform. Currently, it has started 2 sessions of classes with the number of students more than 100 , and page views more than 10,000 . In practice, the instructor issues the key content of the teaching in the form of an outline, questions or a teaching video, and asks the students to preview and think before the class. The teacher asks questions in the classroom to examine the effect of student's preview, and focuses on explaining the common difficulties and key issues. For individual questions of individual students, teachers answer through webmail, QQ, message boards or face-to-face Q\&A. This online learning platform is convenient for students to use the fragmentation time for self-learning, which lays a foundation for the implementation of the flipped classroom teaching method, establishes a two-way interactive teaching mode for teachers and students, and creates a friendly and independent learning environment [4].

\section{CONCLUSION}

The teaching mode of the clothing IE course connecting the clothing manufacturing enterprises in Ningbo has the following characteristics:

- Strengthening Practical Teaching. Only when theoretical knowledge is put into practice can students truly master the skills. As a professional course in higher vocational colleges, in the process of curriculum construction, practice teaching has always been the focus. It is necessary to continuous explore to carry out classroom practice teaching and enterprise practice through informatization, schoolenterprise cooperation, etc. to achieve the successful introduction of the local clothing industry in Ningbo in the practice teaching link. 
- Developing Close and Diversified Cooperation with Ningbo Garment Enterprises to Realize the Joint Construction of Each Link of the IE Curriculum. Apparel companies are closely integrated into the curriculum practice, graduation design, internship, teacher teaching and research projects, and the construction of informational teaching resources and platforms. At the same time, each link also cooperates with each other. The intersection and integration between course teaching and post-internship and graduation design realizes the coherence of curriculum practice. The connection between student graduation design and teachers' teaching and research projects improves students' ability to solve practical problems and conduct scientific research; teachers can also build teaching information resources and platforms with the help of students' internship links and teaching and research projects; and the construction of teaching information resources and platforms can be applied to classroom teaching. All links complement each other and build and develop together, as shown in "Fig. 3".

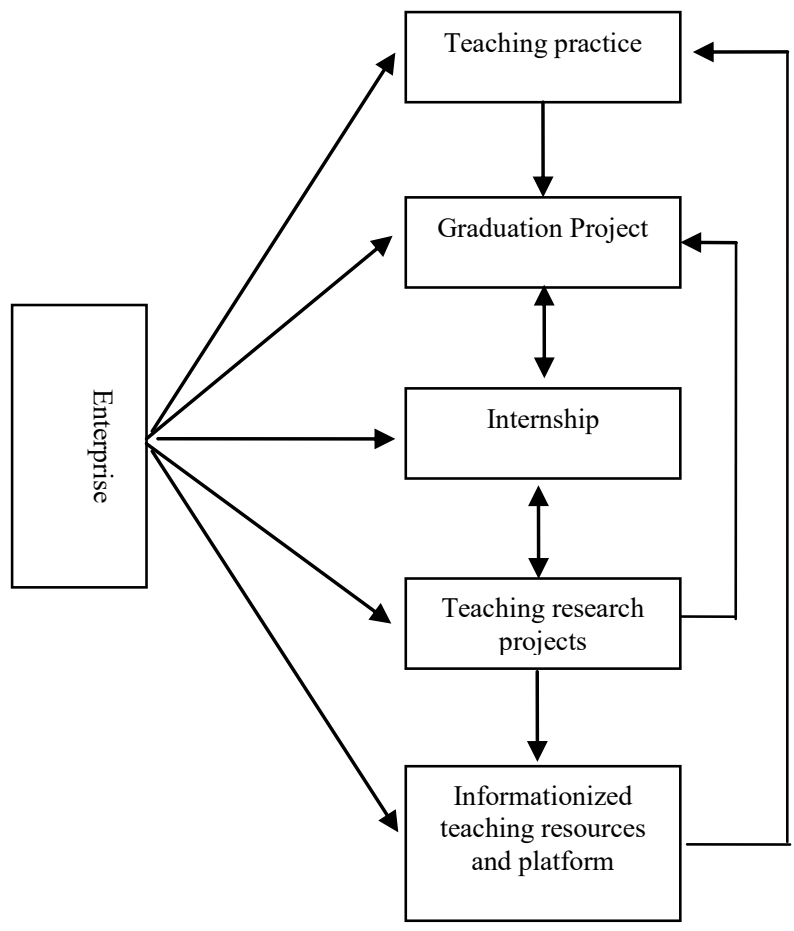

Fig. 3. The joint construction of each link of the IE curriculum.

- Based on the information means and the innovative teaching mode of flipped classroom teaching, the traditional teaching and learning mode has been changed, which provides a good learning environment for students' independent learning and teachers' innovative teaching. It can also be used as an idea for modernization reform of other teaching methods.

The direction of the further development of clothing IE course in the future:
We will vigorously support the research projects of college students and build the student projects serving the development of IE technology in Ningbo apparel enterprises. The development of student projects can also enrich the content of curriculum design and graduation design, provide a basis for the reform and innovation of curriculum design and graduation design, encourage students to publish papers in public journals, and use the available resources to create conditions for students' scientific and technological innovation activities.

\section{REFERENCES}

[1] Zhang Shuntang, Zhang Daiqin. Comparison of undergraduate talent training curriculum system of industrial engineering at home and abroad. Journal of Shandong Institute of Business and Technology [J].2012(10):115-119. (in Chinese)

[2] Li Erliang. Analysis of Practical Teaching of Industrial Engineering major with Textile and Garment Characteristics[J]. Journal of Beijing electric power college. 2011(6):3-4. (in Chinese)

[3] Wang Enliang. Industrial Engineering Handbook [M]. Beijing: China Machine Press, 2006: 1,16. (in Chinese)

[4] Chen Yarong, Zhou Hongming, Fu Peihong, Li Fengping. Course Teaching Model of Applied IE Talents Training for Regional Industrial Clusters[J]. Industrial Engineering, 2009(4):122-125. (in Chinese)

[5] Guo Wei. The latest evolution of industrial engineering courses [J]. Industrial Engineering and Management, 2005 (2): 1-5. (in Chinese) 